\title{
ASSESSMENT OF PRECAST WIDE U BEAM- COLUMN SYSTEM FOR MITIGATION OF STRUCTURAL FAILURE FROM SEISMIC HAZARD IN THAILAND
}

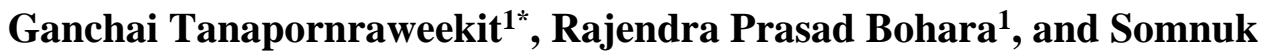 \\ Tangtermsirikul ${ }^{2}$ \\ ${ }^{1}$ Construction and Maintenance Technology Research Center, School of Civil Engineering and Technology, \\ Sirindhorn International Institute of Technology, Thammasat University, Pathumthani, Thailand, \\ e-mail: ganchai@siit.tu.ac.th, rajendra@siit.tu.ac.th \\ ${ }^{2}$ School of Civil Engineering and Technology, Sirindhorn International Institute of Technology, Thammasat \\ University, Pathumthani, Thailand, e-mail: somnuk@siit.tu.ac.th
}

Received Date: September 22, 2020 Revised Date: March 20, 2021; Acceptance Date: May 7, 2021

\begin{abstract}
A large number of low to moderate earthquake incidents have been witnessed in the northern and western parts of Thailand. These incidents usually lead to various damage levels in various structures. Therefore, a sufficient lateral force resisting structures should be designed for the construction in such earthquake-prone areas. This paper presents the relevance of using a typical composite wide $\mathrm{U}$ beam-column system for mitigation of structural failure and collapse from the seismic hazard in Thailand. The investigated composite structural system consists of precast $U$ beams, precast columns, and cast-in-situ concrete over the precast $U$ beams and in the joint regions. The system also includes post-tensioning in the cast-in-situ area of the composite beams. The system has widely been used in low- to mid-rise commercial building in Thailand. In order to scrutinize the seismic performance of the system, a half-scale specimen of the post-tensioned precast $U$ beam-column joint was tested under an incremental displacement-controlled lateral cyclic load. The laboratory test revealed the drift capacity, damage pattern, strain development in the rebars etc. of the precast wide U beam-column interior joint. Based on the obtained drift capacity, displacement-based assessment of the system was carried out. In addition, the observed damages on the tested structure were evaluated using damage grading criteria for building subjected to earthquake. The assessment showed a high potential of the post-tensioned precast wide $U$ beam-column system to mitigate the structural failure and collapse from the earthquake hazard. However, some improvements in the current seismic performance of the system are required to employ the system in high seismic zones.
\end{abstract}

Keywords: Beam-column joint, Damage assessment, Precast U beam, Seismic hazard

\section{Introduction}

Earthquake is a natural hazard with a number of extreme incidents such as ground vibration and rupture, landslide, liquefaction, and tsunami [1]. Each of these effects can cause disaster to the human society, if appropriate mitigation techniques are not well implemented. Among various effects of earthquake, structural failure and collapse due to ground shaking is one of the major causes of human and economic losses [2]. Therefore, a special attention is paid to the design and construction of earthquake resistant structures. It is noted that design and detailing of the structures are required to be in accordance with level of the seismicity in order to preclude over- or under-design of the structures [3]. 
Although Thailand is located in a low and sparse seismicity area, a number of small to moderate earthquakes have been reported [4]. These earthquakes lead to various levels of damage in various structures. For example, the Mae Lao earthquake in 2014 affected a total of 10,863 buildings to various degrees of damage [5]. A report by the Department of Public Works and Town \& Country Planning [6] showed that out of 10,863 buildings, the number of unsafe, repairable and minorly damaged buildings were 594, 2,376 and 7,893, respectively. In order to prevent and mitigate such devastation, a robust lateral load resisting system against seismic load is required for such earthquake-prone areas. Also, the use of precast construction is gaining popularity in Thailand. Therefore, this paper investigates the potential of a precast wide $U$ beam-column system as one of the possible lateral load resisting frames for buildings in Thailand.

Precast wide U beam-column system is a composite system, which consists of precast columns, precast $U$ beams with post-tensioned cast-in-situ concrete. This system possesses several advantages over the traditional beam-column system, e.g., lower interstory height, faster construction, elimination of formworks and economical construction.

Precast wide $\mathrm{U}$ beam-column system has been widely used in low- to mid-rise commercial buildings in Thailand. However, actual seismic performance of this system is yet to be revealed. Bohara et al. (2019) [7] and Bohara et al. (2018) [8] carried out numerical investigations on the seismic performance of post-tensioned precast wide $\mathrm{U}$ beam-column interior and exterior joints, respectively. Since the numerical models were based on some assumptions, experimental study is essential to reveal the actual seismic performance of the system. Therefore, this paper aims to experimentally evaluate the performance of the posttensioned precast wide $\mathrm{U}$ beam-column system. The obtained experimental results are assessed with respect to the seismicity of Thailand. A simple but rational and practical approach is implemented to classify the damage on the tested structure subjected to seismic loading. Based on the displacement-based assessment and damage grading, the potential of the precast wide $U$ beam-column system for prevention and mitigation of structural failure is evaluated.

In this paper, seismic performance of the post-tensioned precast wide $\mathrm{U}$ beamcolumn system is evaluated with respect to the drift capacity and consequent damage levels under lateral cyclic loading. A half-scale interior beam-column joint of the system was tested under a quasi-static lateral cyclic loading. In order to determine the suitability of the system in various seismic zones of Thailand, a displacement-based assessment was carried out with respect to the drift capacity of the joint. Furthermore, the observed crack and damage patterns were investigated to assess the potential of the system to mitigate structural failure and damage from seismic hazard in Thailand.

\section{Details of Precast Wide U Beam-Column System}

The major components of precast wide $\mathrm{U}$ beam-column system are precast $\mathrm{U}$ beams and slabs with embedded A-trusses, precast columns and cast-in-situ concrete with posttensioning. It is noted that the A-trusses work as a shear connection between the precast and the cast-in-situ concrete. Figure 1 shows the precast $\mathrm{U}$ beam and slab with A-trusses.

The construction methodology of the precast wide $\mathrm{U}$ beam-column system is as follows. First, the precast concrete lower storey columns with extended longitudinal rebars are erected. These extended rebars are inserted into the mechanical splices installed in the upper storey column, which are, finally, filled up by grout injection. 


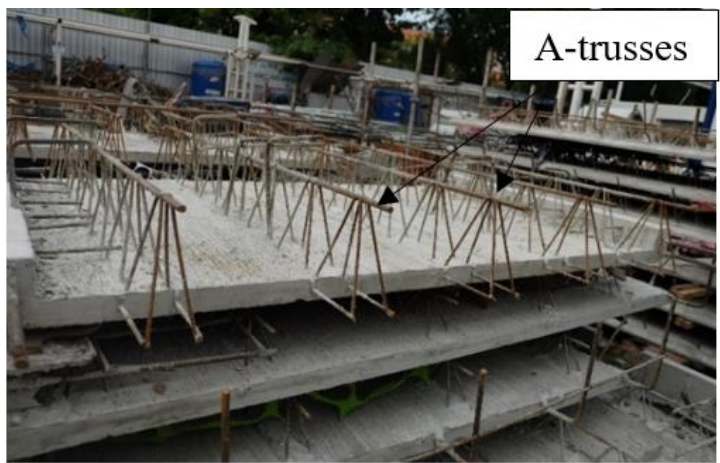

a. Precast U beam

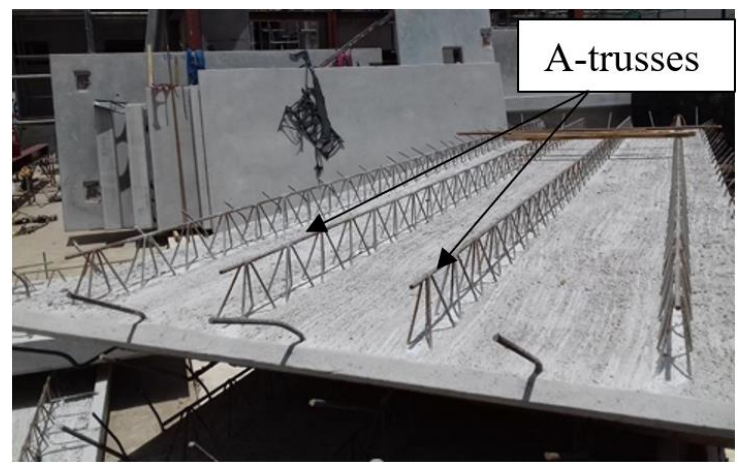

b. Precast slab

Figure 1. Precast U beam and precast slab with A-trusses

After the erection of columns of a lower storey, scaffolding is set up and the precast panels are installed over it. The precast wide $U$ beams are laid along the weak axis of the building and the one-way precast slab panels are spanned on these U-beams. These precast panels (U beam and slab) serve as permanent formworks. It is worth noting that no precast member is used in the vicinity of the joint but only the cast-in-situ concrete is used in the joint region. The adoption of cast-in-place concrete only in the joint region is expected to ameliorate the structural integrity of the precast system. A typical layout of the precast $U$ beams and precast slabs during construction is shown in Figure 2.

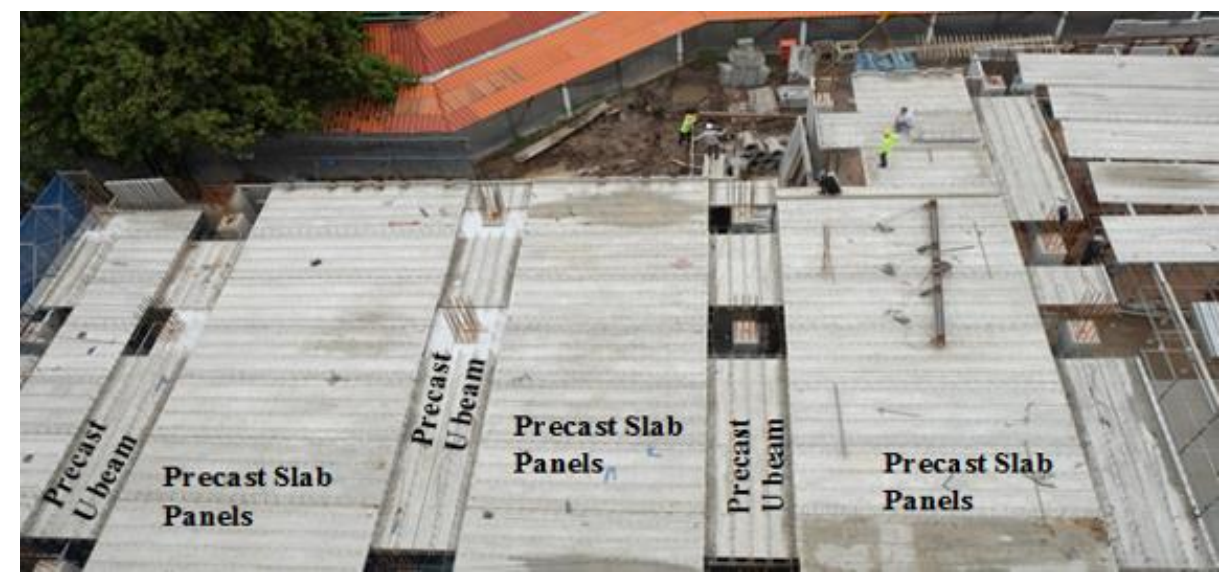

Figure 2. Precast U beam-column system during construction

After the installation of precast members and formwork in the joint region (as shown in Figure 2), joint reinforcements, beam rebars, and post-tension cables are set up. Then, cast-in-situ concrete is poured over the precast members. Post-tensioning is applied to the installed cables four days after casting of the cast-in-situ concrete.

\section{Experimental Program}

\section{Specimen Details}

In order to investigate the seismic performance of the precast wide $\mathrm{U}$ beam-column system, a half-scale specimen of an interior joint of the system was tested in our laboratory. It is noted that the tested specimen represents beam-column joints used for Advanced Laboratory 
Building of Sirindhorn International Institute of Technology, where the investigated joint is between two unequal spans. Therefore, the tested specimen has unequal beam span lengths. The details of the half-scale specimen are presented in Figure 3.

A precast column with dimensions of $300 \mathrm{~mm} \times 400 \mathrm{~mm} \times 1800 \mathrm{~mm}$ consists of $12-$ DB16 rebars as longitudinal rebars and 3-RB6@100mm as lateral ties. Four PVC pipes with a diameter of $25 \mathrm{~mm}$ are provided in the precast column to insert pre-stressing tendons (see Figure 3a). The elevation sizes of the half-scale composite wide beam are $180 \mathrm{~mm} \times 1000 \mathrm{~mm}$, which consist of two layers of concrete (50mm precast and $130 \mathrm{~mm}$ cast-in-situ). RB6 U bars@150 mm and three rows of RB6 A-trusses are rooted in the precast U beam (see Figure 3b). At the top and bottom of each A-truss, additional RB6 bars are welded. At the corner of precast U beam, 2-RB9 rebars are installed and tied with RB6@100mm bars. 7-RB6 bars are provided throughout the span as top longitudinal bars. Furthermore, RB6 rebars are distributed at the spacing of $250 \mathrm{~mm}$ in transverse direction.
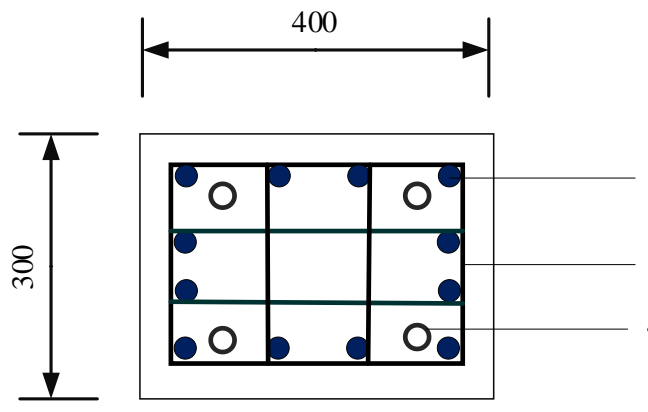

12-DB16 Longitudinal bars

3-RB6 lateral ties@100mm

4- $\$ 25$ PVC pipes for tendons

a. Details of precast column

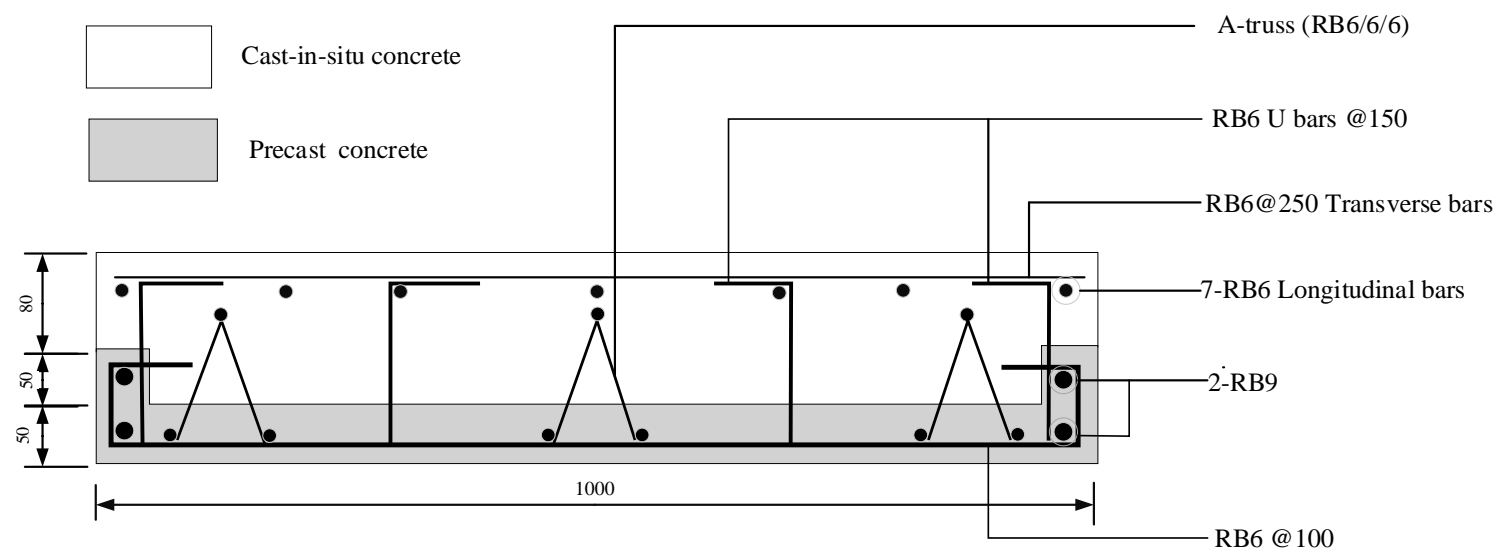

b. Details of wide beam

Figure 3. Details of precast column and composite wide beam (unit: $\mathrm{mm}$ )

As shown in Figure 4, three layers of 6-RB9 rebars having a length of $1.5 \mathrm{~m}$ are distributed in the joint region. On the top reinforcement layer in the joint region, extra 6 RB9 rebars with a length of $1.5 \mathrm{~m}$ are provided. Also, 4-DB12 bars are provided in both longitudinal and transverse directions of the joint. The spacing of $U$ bars is reduced to $100 \mathrm{~mm}$ in the joint region. 
7-wire 2-strand tendons with a parabolic profile were used to prestress the U-beam. The layout and profile of the tendons are presented in Figure 5. It is worth mentioning that an extra $250 \mathrm{~mm}$ cast-in-situ concrete was added at prestressing end of the beam in order to provide a uniform prestressing force to the section of the wide beam. Therefore, distances of clamps from beam ends on short and long spans are $550 \mathrm{~mm}$ and $300 \mathrm{~mm}$, respectively.

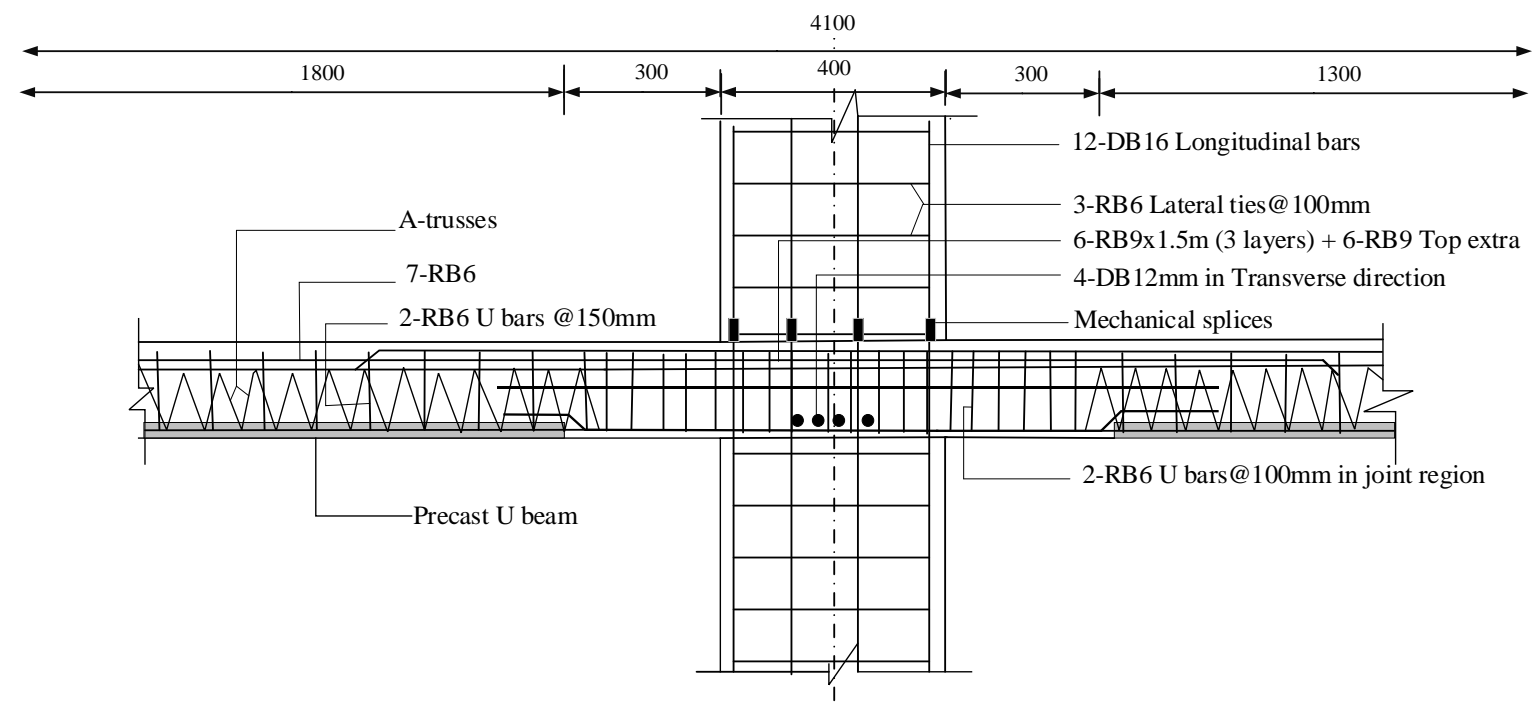

Figure 4. Longitudinal section of precast wide U beam-column interior joint (unit: $\mathrm{mm}$ )

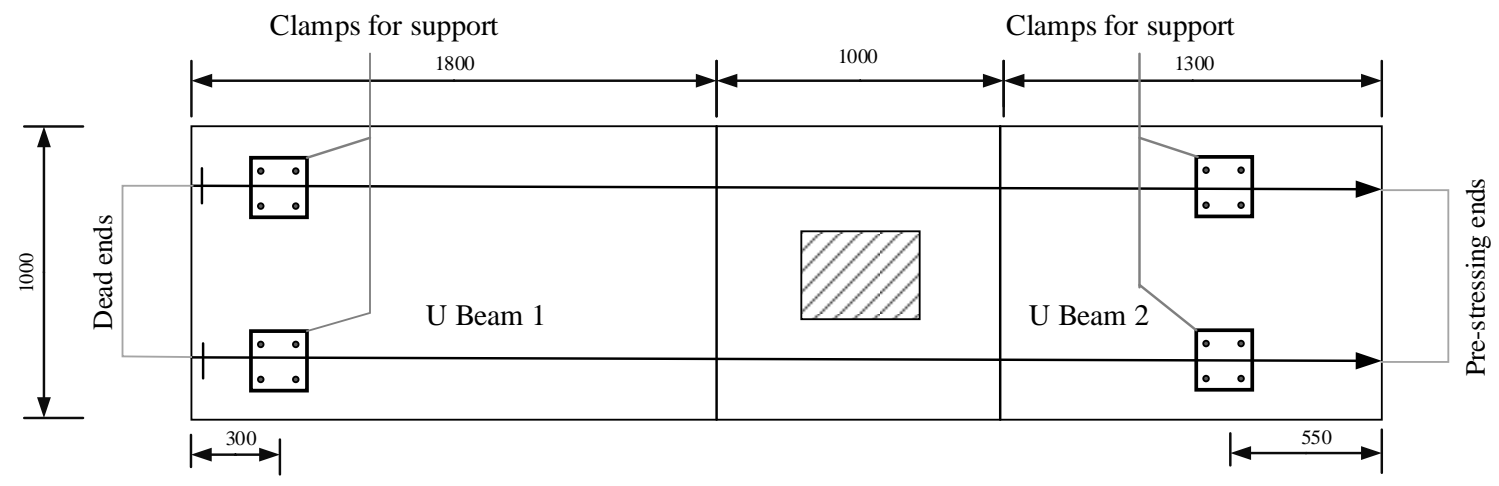

a. Tendon layout

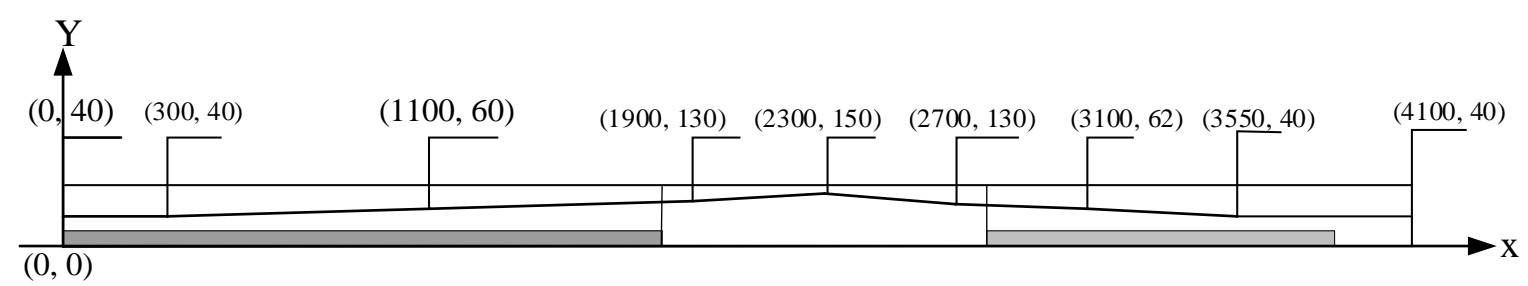

b. Tendon profile

Figure 5. Details of tendons (unit: $\mathrm{mm}$ ) 


\section{Test Set up and Loading}

Similar to the previous researches [9][10], only the portion between inflection points was prepared and set up for the testing. The ends of the beam were supported with rollers whilst hinge support was assigned at the column base. An axial load on the column was applied through four prestressed tendons. Each tendon was subjected to an axial load of 9.8 tons. The application of the axial load on the column represents the gravity load from upper stories. A detailed illustration of the test set up is shown in Figure 6.

The specimen was subjected to incremental displacement-controlled laterally cyclic load. The applied drifts were $\pm 0.10 \%, \pm 0.35 \%, \pm 0.60 \%, \pm 0.85 \%, \pm 1.10 \%, \pm 1.35 \%$, $\pm 1.85 \%, \pm 2.35 \%, \pm 2.85 \%, \pm 3.85 \%$ and $\pm 4.85 \%$. Each drift cycle was applied twice $(2$ cycles in each drift). During the test, lateral force reaction, lateral displacement of the top column, crack propagation, crack widths and strains in the rebars were recorded.

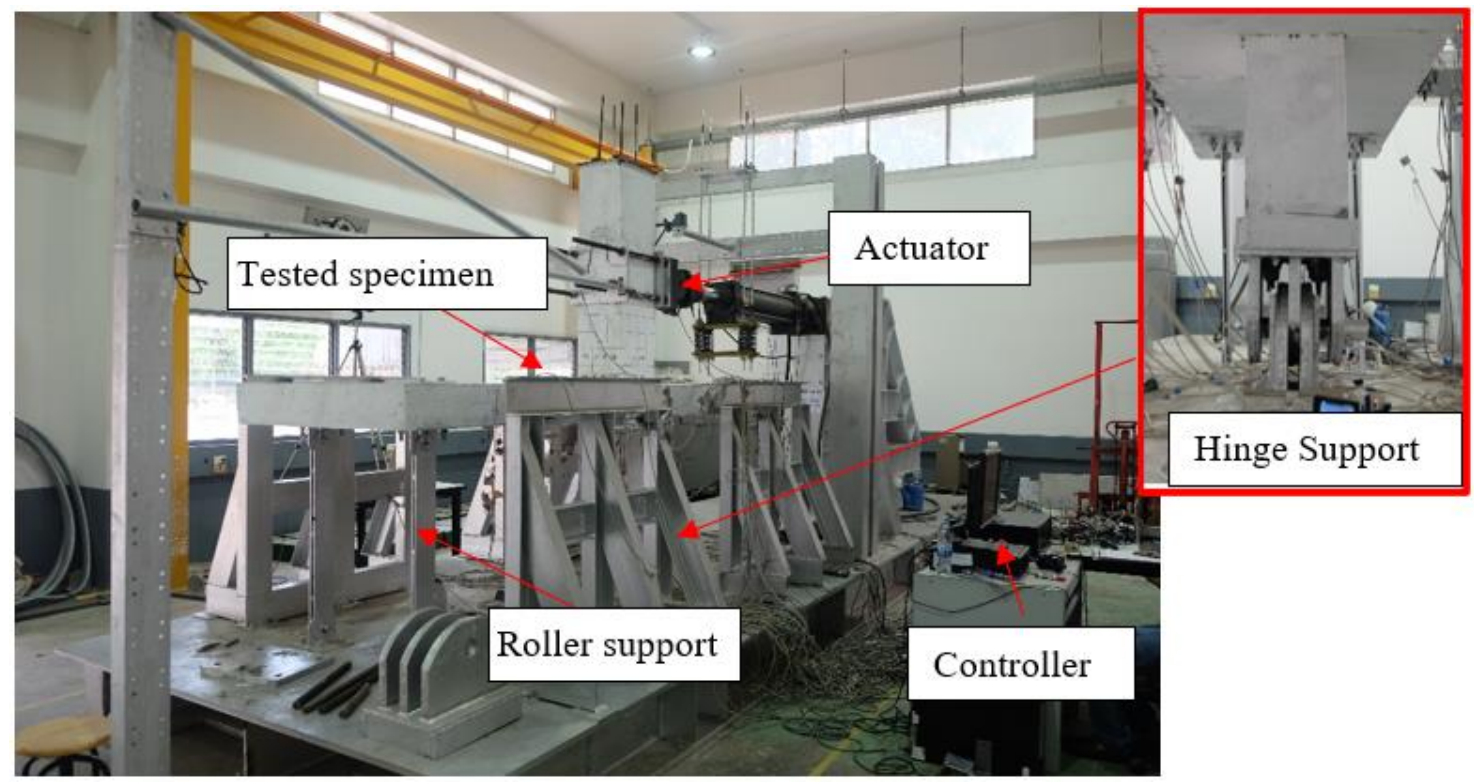

Figure 6. Test set up of the wide $\mathrm{U}$ beam-column joint specimen under lateral cyclic load

\section{Displacement-based Assessment}

The damage and failure of a structure under lateral load take place when it reaches certain limit inter-story drift. Therefore, it is preferable to compare the inter-story drift demand and the drift capacity of the building [11]. In addition, displacement-based assessment of the structure directly links the structural performance to the ground motion, and provides the practical medium to relate the laboratory results to the real structural performance in the site during seismic events.

The drift demand of the structure is the function of seismicity of the building site location and characteristics of the structure. In displacement-based assessment of the structure, the inter-story drift demand of the structure is calculated based on the specific earthquake data and characteristics of the building. On the other hand, the drift capacity of the structure is evaluated by experiment or numerical analysis or analytical calculation. Then, the drift capacity and drift demands are compared to assess the performance of the structure for a specific seismic event. Alternatively, the safe PGA corresponded to the drift capacity of the system can be compared with the actual PGA during a particular earthquake. 
In this study, similar to Goldworthy and Abduka (2012) [12], an elastic spectral pseudo acceleration shape was assumed for firm ground site locations. In the assumed elastic spectral pseudo acceleration, a transition of constant acceleration to constant velocity was considered to take place at $0.5 \mathrm{sec}$ with a damping of $5 \%$ of the critical damping.

Based on the moment magnitude of earthquake $(\mathrm{Mw})$, a corner period of the displacement spectra $\left(\mathrm{T}_{\mathrm{c}}\right)$ is calculated using Equation 1.

$$
\mathrm{T}_{\mathrm{c}}=1+2.5(\mathrm{Mw}-5.7) \quad \text { in second }
$$

Drift capacity $\left(\theta_{\max }\right)$ obtained from the experiment is used to estimate the displacement capacity at effective height $\left(\Delta_{\mathrm{f}}\right)$ by using Equation 2.

$$
\theta_{\max }=\mathrm{F}_{\theta} \frac{\Delta_{\mathrm{f}}}{\mathrm{H}_{\mathrm{e}}}
$$

In Equation 2, $\mathrm{F}_{\theta}$ which accounts for higher modes and stiffness variation in different stories is taken to be 1.3 [9]. $\mathrm{H}_{\mathrm{e}}$ is the effective height of the building which can be calculated from $0.66 \mathrm{H}_{\mathrm{n}}$, where $\mathrm{H}_{\mathrm{n}}$ is the height of the building.

Based on fundamental period of building, $\mathrm{T}_{\mathrm{f}}\left(=0.1 \mathrm{H}_{\mathrm{n}}\right)$ and $\mathrm{T}_{\mathrm{c}}$, suitable equations (Equation 3 or 4 ) for $\Delta_{\mathrm{f}}$ is selected and maximum elastic response displacement $\left(\Delta_{\mathrm{TC}}\right)$ is calculated.

$$
\begin{array}{lll}
\Delta_{\mathrm{f}}=\Delta_{\mathrm{TC}} \frac{\mathrm{T}_{\mathrm{f}}}{\mathrm{T}_{\mathrm{c}}} & \left(\text { if } \mathrm{T}_{\mathrm{f}} \leq \mathrm{T}_{\mathrm{c}}\right) & \text { in meter } \\
\Delta_{\mathrm{f}}=\Delta_{\mathrm{TC}} & \left(\text { if } \mathrm{T}_{\mathrm{f}}>\mathrm{T}_{\mathrm{c}}\right) & \text { in meter }
\end{array}
$$

Finally, the safe PGA on the firm soil with respect to an earthquake of moment magnitude $\mathrm{M}_{\mathrm{w}}$ is estimated by using Equation 5 .

$$
\mathrm{PGA}=\frac{\Delta_{\mathrm{TC}}}{0.031 \times\left(1+2.5\left(\mathrm{M}_{\mathrm{W}}-5.7\right)\right)} \quad \mathrm{m} / \mathrm{s}^{2}
$$

\section{Results and Discussion}

\section{Determination of Drift Capacity of the System}

The hysteresis curve (force-displacement) obtained from the experiment is shown in Figure 7. The solid and dashed lines in Figure 7 represent the hysteresis curves for the first cycle and second cycle of loading, respectively. The tested post-tensioned precast wide U beamcolumn interior joint exhibited the drift capacity (drift at peak load) of $3.35 \%$ and $2.85 \%$ in positive and negative cycles, respectively. The asymmetric drift capacity of the joint was mainly due to its unequal beam span lengths. The specimen was tested till $4.85 \%$ drift in both positive and negative cycles.

After attaining the peak load, the specimen exhibited a rapid load drop (28\% of the peak load) with the increased drift ratio. Crushing of concrete was observed on the wide beam near the column face. Ductility factor $(\mu)$, which is the ratio of ultimate displacement $\left(\Delta_{\mathrm{u}}\right)$ to yield displacement $\left(\Delta_{\mathrm{y}}\right)$, was adopted to evaluate ductility of the structure. As per JSCE guideline [13], $\Delta_{\mathrm{y}}$ is the displacement when the main tensile reinforcement yields, and $\Delta_{\mathrm{u}}$ is the maximum displacement at which load is equal to yield strength. Definition of $\Delta_{\mathrm{y}}$ 
and $\Delta_{\mathrm{u}}$ are presented in Figure 8a [13]. The values of $\Delta_{\mathrm{y}}$ and $\Delta_{\mathrm{u}}$ for the tested specimen are shown in Figure 8b. It is worth mentioning that longitudinal bars of both column and beam yielded at $2 \%$ drift, which was equivalent to the lateral displacement of $36 \mathrm{~mm}$. More details of the measured strain in rebars will be presented in the section "Strain Development in the Joint Core".

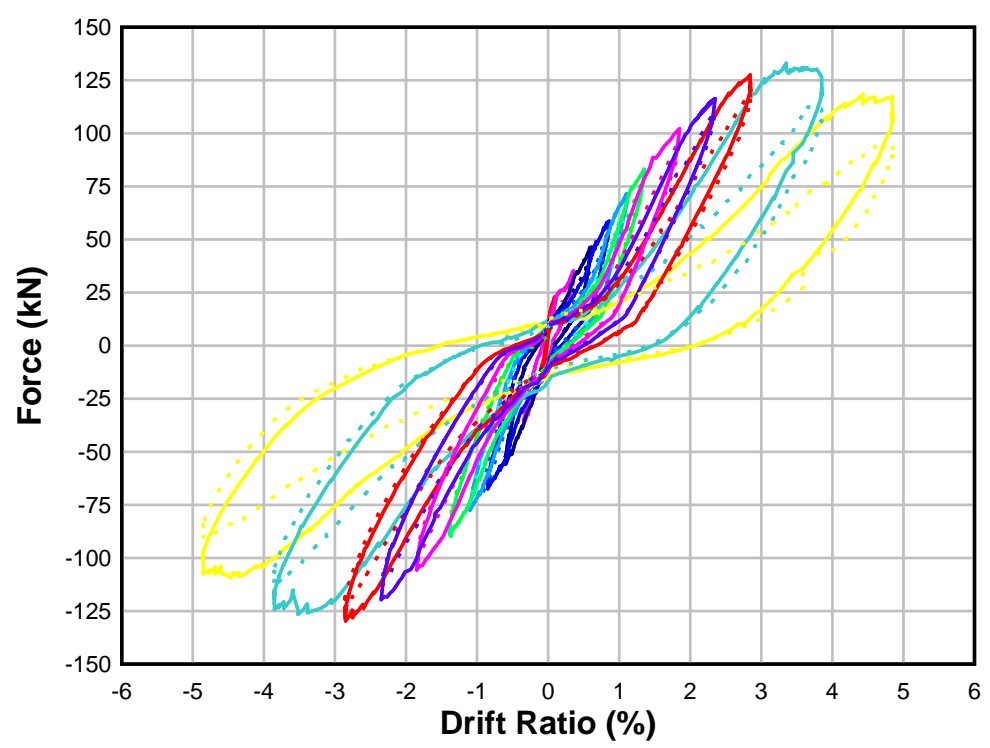

Figure 7. Hysteresis curve

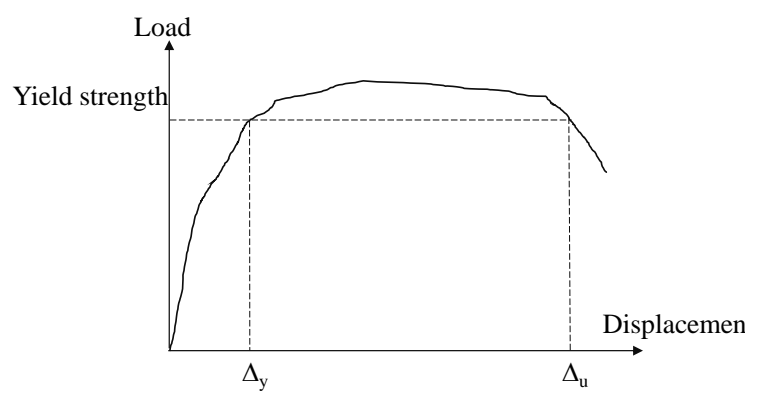

a. Definition of $\Delta_{\mathrm{y}}$ and $\Delta_{\mathrm{u}}[13]$

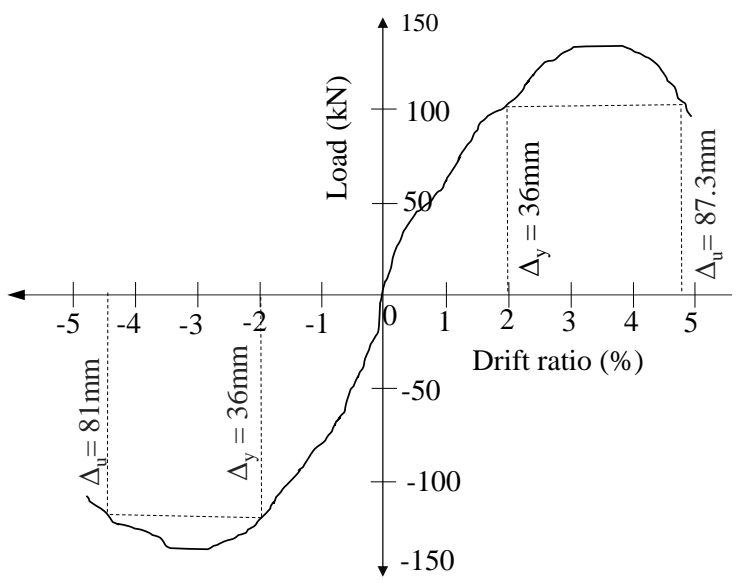

b. $\Delta_{\mathrm{y}}$ and $\Delta_{\mathrm{u}}$ of the tested specimen

Figure 8. Yield and ultimate displacement of the specimen

Based on the above-mentioned criteria, the values of $\mu$ were obtained to be 2.42 and 2.25 in positive and negative loading cycles, respectively. A value of $\mu$ greater than 1 and less than 1.25 represents a nominally ductile structure. Limited ductile structure and ductile structure exhibit $\mu$ in the range of 1.25 to 3 , and 3 to 6 , respectively [14]. Therefore, the tested structure exhibited a limited ductile behavior. Furthermore, the thin hysteresis loops indicate poor energy dissipation of the system under this loading action. Therefore, some modifications in structural detailing of the specimen are required in order to make the system more ductile and be able to exhibit a higher energy absorption. 


\section{Displacement-based Assessment}

The drift capacity of the joint obtained from the experiment was used for the assessment. Between the two drift capacities (in positive and negative cycles), the lower one (2.85\%) was used for the assessment.

The ground motion parameters for Thailand were adopted from Ornthammarath et al. (2011) [4], Warnitchai and Lisantono (1996) [15], and Pailoplee and Charusiri (2016) [16]. In this assessment, based on the study of historical seismicity data from 1912 to 2007 presented by Ornthammarath et al. (2011) [4], a 7.0 $\mathrm{M}_{\mathrm{w}}$ earthquake was taken to be a possible maximum magnitude of earthquake in Thailand. A probabilistic seismic hazard (PSH) map based on 50 -year return period and $2 \%$ probability of being exceeded by Pailoplee and Charusiri (2016) [16] were the basis for adoption of peak ground acceleration (PGA). Based on the study by Pailoplee and Charusiri (2016) [16], 0.50g was taken as the maximum PGA for Thailand. A summary of ground motion parameters to cover an entire area of Thailand is shown in Table 1.

Table 1. Ground Motion Parameters to Cover an Entire Area of Thailand

\begin{tabular}{lll} 
Parameters & Notation & Value \\
\hline Moment magnitude of earthquake & $\mathrm{M}_{\mathrm{w}}$ & 7.0 \\
Peak ground acceleration & PGA & $0.5 \mathrm{~g}$ \\
\hline
\end{tabular}

An eight-storey building with $3.6 \mathrm{~m}$ story height was considered as an example for the analysis. Therefore, the height of the building $\left(\mathrm{H}_{\mathrm{n}}\right)$ was $28.8 \mathrm{~m}$. The building parameters used for the displacement-based assessment are given in Table 2.

By using the equations 1 to 5 and parameters in Table 1 and Table 2, the safe PGAs for the system were estimated. The calculated parameters of displacement-based assessment are presented in Table 3.

Table 2. Building Parameters for Displacement-based Assessment

\begin{tabular}{llll} 
Parameters & Notation & Formulation & Value \\
\hline Fundamental period of building & $\mathrm{T}_{\mathrm{f}}$ & $0.1 \mathrm{H}_{\mathrm{n}}$ & $2.88 \mathrm{sec}$ \\
Effective height of the building & $\mathrm{H}_{\mathrm{e}}$ & $0.66 \mathrm{H}_{\mathrm{n}}$ & $19 \mathrm{~m}$ \\
\hline
\end{tabular}

Table 3. Summary of Calculated Parameters

\begin{tabular}{ll} 
Parameters & Value \\
\hline $\mathrm{T}_{\mathrm{c}}$ & $4.25 \mathrm{sec}$ \\
$\Delta_{\mathrm{TC}}$ & $0.61 \mathrm{~m}$ \\
$\Delta_{\mathrm{f}}$ & $0.42 \mathrm{~m}$
\end{tabular}

Safe PGA for firm soil $0.47 \mathrm{~g}$ 
The safe PGA, thus obtained, is for the firm soil. In order to determine the safe PGA for intermediate and soft soil, the safe PGA was reduced by factors of 1.4 and 1.8, respectively. The obtained safe PGAs for firm, intermediate and soft soil are presented in Table 4.

Table 4. Safe PGAs on Different Soil Types

\begin{tabular}{lcc} 
Soil & $\mathbf{M}_{\mathbf{w}}$ & PGA \\
\hline Firm & & $0.47 \mathrm{~g}$ \\
Intermediate & 7.0 & $0.33 \mathrm{~g}$ \\
Soft & & $0.26 \mathrm{~g}$ \\
\hline
\end{tabular}

These safe PGAs were compared with the contours of PGAs obtained from the PSH map by Pailoplee and Charusiri (2016) [16] (shown in Figure 9). Considering the firm soil condition, the capacity of the tested system fulfils the demand of all zones except the vicinity of Kanchanaburi (P4). However, the drift capacity of the system based on intermediate and soft soil conditions is insufficient in several locations in Thailand. For example, the tested system cannot fulfil the drift demand for the construction in intermediate soil in Tak (P10). In addition, the drift performance of the tested system is insufficient for the soft soil sites in Phuket (P8), Ranong (P9), and many northern areas of Thailand (P2, P3, P5, P6 and P7). Therefore, a modification in the detailing of the system is recommended so that it is able to fulfil the drift demand on all the seismic zones and soil types in Thailand.

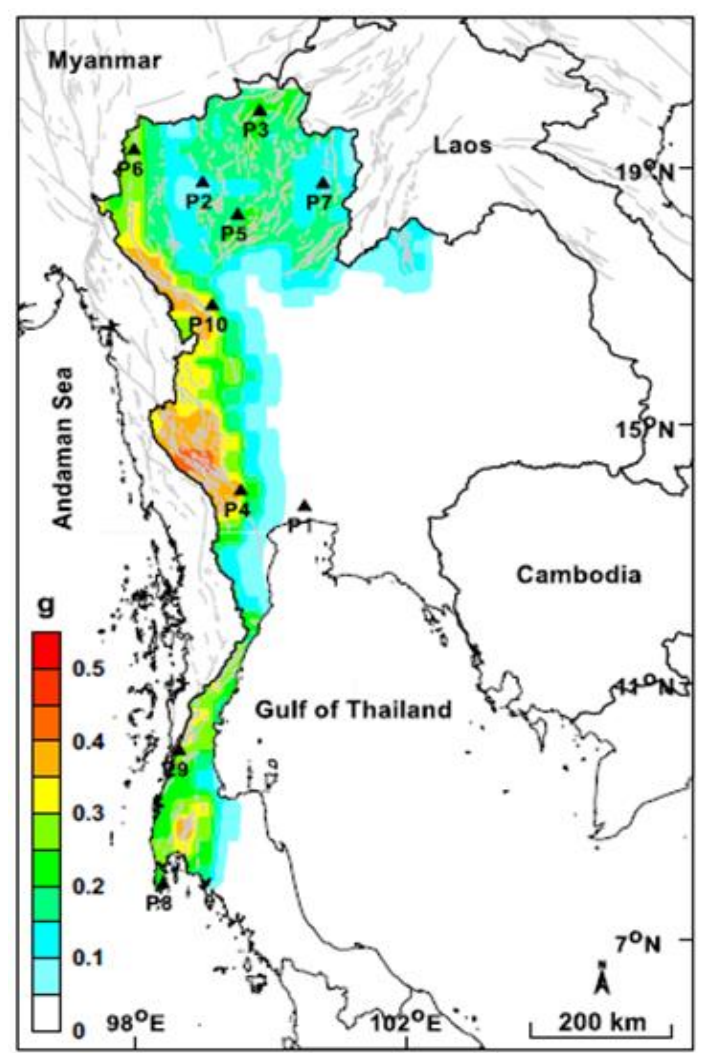

Legends

P1: Bangkok

P2: Chiang Mai

P3: $\quad$ Chiang Rai

P4: Kanchanaburi

P5: $\quad$ Lampang

P6: $\quad$ Mae Hong Son

P7: Nan

P8: $\quad$ Phuket

P9: $\quad$ Ranong

P10: Tak

Figure 9. Contours of PGA for an earthquake of $2 \%$ of probability of being exceedance within the next 50 years (Pailoplee and Charusiri) [16] 


\section{Crack Patterns}

The crack patterns observed at various drift ratios are presented in Figure 10. The tested specimen exhibited the first crack at the second cycle of $0.35 \%$ drift ratio on the longer span (U Beam 1 in Figure 5a). The first crack originated from the bottom face of the wide beam and propagated upward to the upper face of the beam (see Figure 10a). A decrease in the slope of hysteresis curve was observed due to the formation of this crack (see Figure 7).

The first transverse crack on the top face of the wide beam was initiated at the drift ratio of $0.60 \%$ (see Figure 10b). This crack was located exactly above the first crack, which merged with this newly formed crack at $1.10 \%$ drift ratio. These transverse cracks were generated due to flexural action in the beam.

The first diagonal shear crack appeared at the drift ratio of $1.10 \%$ (see Figure 10c). After $1.10 \%$ drift ratio, several diagonal shear cracks were observed on both short and long spans of the tested joint specimen. Two diagonal cracks crossing each other on the beam near side face of the column appeared at the drift ratio of 1.85\% (see Figure 10d). With the increasing drift ratio from $1.85 \%$ to $3.85 \%$, these cracks became longer and reached the outer edge of the beam at 3.85\% drift ratio (see Figure 10f). These cross-cracks in the joint witnessed the presence of torsional force in the joint vicinity when subjected to lateral cyclic load.

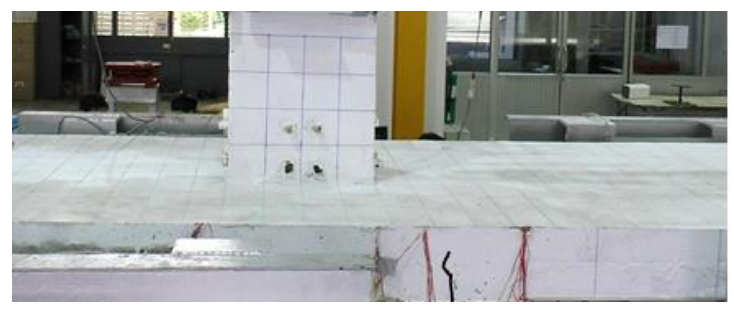

a. Drift Ratio $0.35 \%$

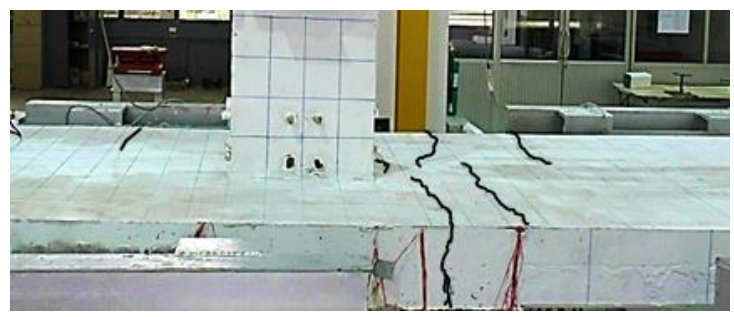

c. Drift ratio $1.10 \%$

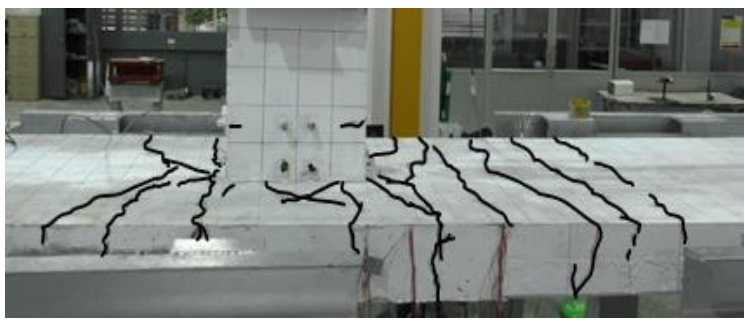

e. Drift Ratio $2.35 \%$

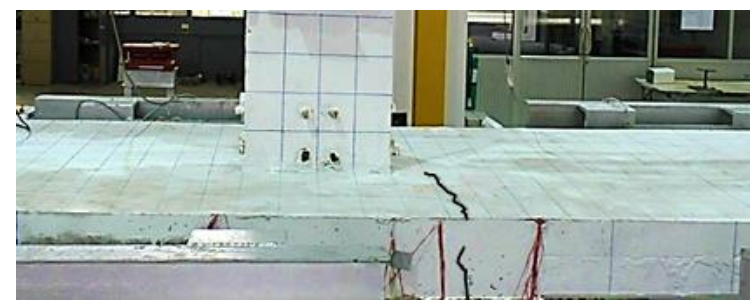

b. Drift ratio $0.60 \%$

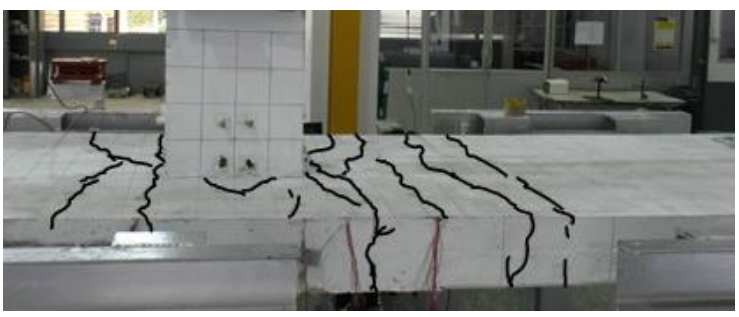

d. Drift ratio $1.85 \%$

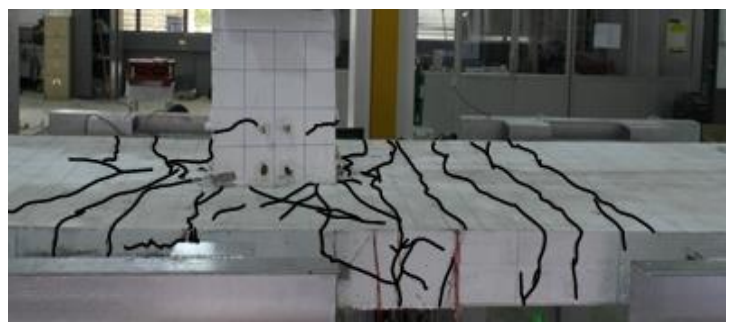

f. Drift Ratio 3.85

Figure 10. Crack patterns at various drift ratios 
Even though the wide beam experienced severe damage, there is no significant damage on the column up to $4.85 \%$ drift ratio. The diagonal shear cracks and transverse flexural cracks were the major crack types observed on the tested beam-column joint structure. Based on the observed damage on the tested specimen, it is worth mentioning that the specimen showed a strong column - weak beam behaviour. Only minor flexural cracks were observed on the column and there is no sign of rebar buckling failure in the column during the lateral cyclic load test. However, in addition to the aforementioned cracks, wide beam exhibited crushing. The crack pattern and crushing of concrete around the joint region of the tested specimen at $4.85 \%$ drift ratio is shown in Figure 11.

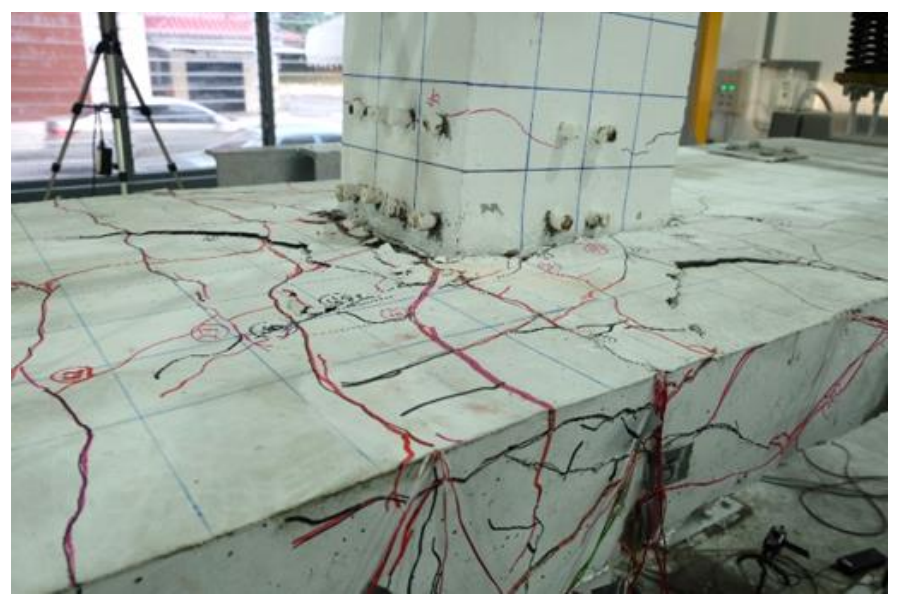

Figure 11. Crack pattern and concrete crushing around the joint region of the tested specimen at $4.85 \%$ drift ratio

\section{Strain Development in the Joint Core}

Beam-column joint core plays a vital role in maintaining the safety of a building frame. Therefore, design of an intact joint core is essential for a robust lateral load resisting structural system. In order to examine the behavior of the joint core of the tested specimen, strain gauges were attached on the longitudinal bars in the column of the joint region. The strain development in the column longitudinal reinforcement bars at different locations, and the first yielding of the longitudinal bar in beam are presented in Figure 12 and Figure 13, respectively.

Among the measured rebars, depending on the location the column cross section, the rebars yielded at different drift ratios. The rebar 'a' yielded first at $2.00 \%$ drift ratio in negative cycle and $2.15 \%$ drift ratio in positive cycle. Then, the rebar ' $b$ ' yielded at $3.00 \%$ drift ratio in both cycles. The rebar ' $c$ ' reached the yielding strain at $4.85 \%$ drift ratio in the negative loading cycle only. This deviation of strain in positive and negative loading cycles was mainly due to asymmetric span lengths of the beam. During the early cycles of lateral load, strain measured at different rebars did not exhibit a significant difference. However, strain of different rebars varied remarkably after $1.50 \%$ drift ratio. In comparison to the mid rebar (rebar ' $a$ ' in Figure 12), the corner rebars showed smaller strain in the joint core. This behavior was due to the presence of prestressed tendons (used to apply axial load to the column) near the corner rebars. Since some part of the tensile stress in the joint core is carried by the tendons, strains in the nearby longitudinal rebars was found to be lower than those in other positions. 


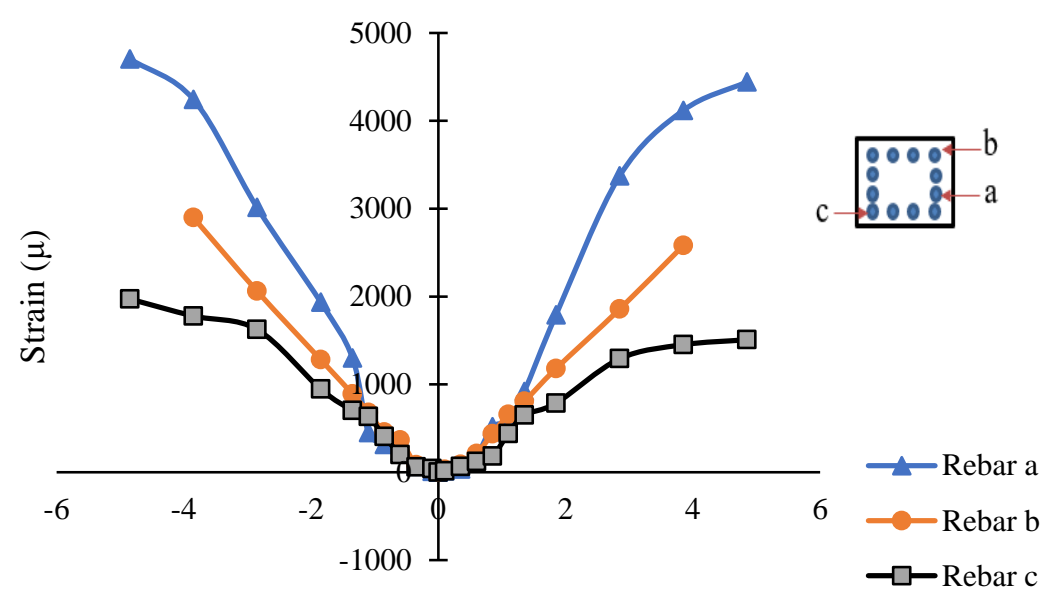

Drift ratio $(\%)$

Figure 12. Strain development in the column rebars in the joint core

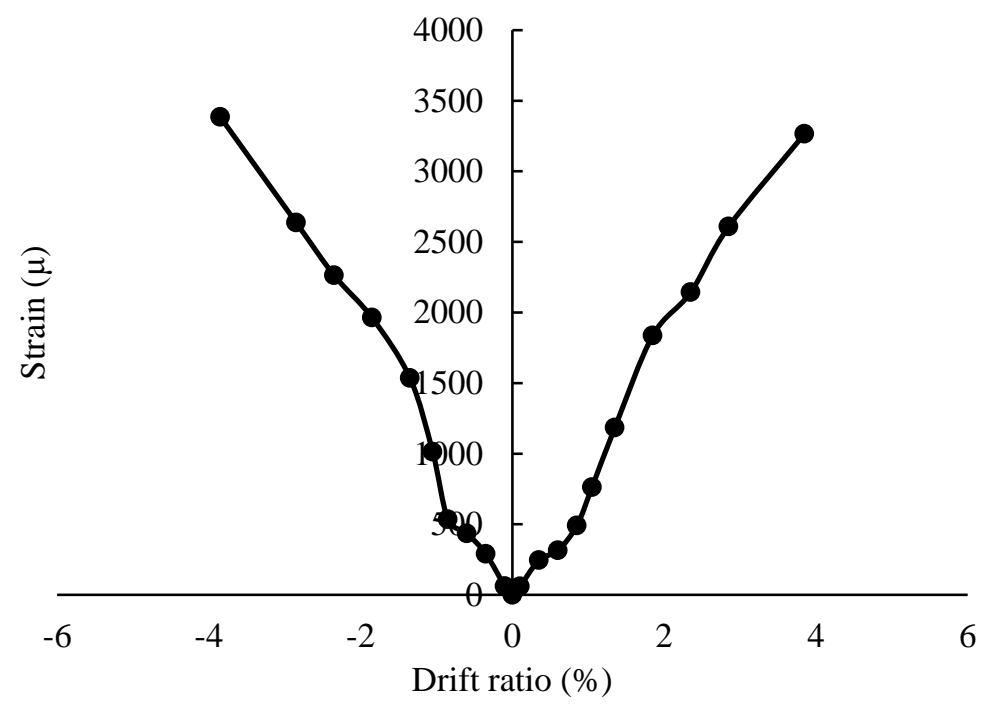

Figure 13. Strain development in the beam longitudinal bar passing through the joint core

The yielding of rebars in the joint core can introduce some damages in the joint core, which should be prevented. Therefore, some improvements in the detailing of the joint core are required to apply to the system constructed in a high seismic zone. In this system, the width of the beam is wider than that of the column. As a result, bending stresses generated due to cyclic loading in the outer zone (away from column) of beam cannot be directly transmitted to the column core. These residual bending stresses on beam generate torsion. Therefore, additional reinforcement to account for this torsion should be considered for modification of reinforcement detailing in the future. It is noted that the torsional cracks can be observed in Figure 10d, 10e and 10f.

\section{Damage Level Grading}

The Japan Building Disaster Prevention Association [17] classifies damage levels on structural members into five classes. A summary of the damage levels on the structural member in different damage classes is presented in Table 5. 
Table 5. A Summary of Damage Classes and Respective Damage Levels on Structural Members [18]

\begin{tabular}{|c|c|}
\hline Damage Class & Damage Level on the Structural Member \\
\hline I & $\begin{array}{l}\text { - A few cracks having width smaller } \\
\text { than } 0.2 \mathrm{~mm}\end{array}$ \\
\hline II & $\begin{array}{l}\text { - Visible cracks having width in the } \\
\text { range of } 0.2-1.0 \mathrm{~mm}\end{array}$ \\
\hline III & $\begin{array}{l}\text { - Spalling of concrete covering } \\
\text { - } 1.0-2.0 \mathrm{~mm} \text { wide cracks }\end{array}$ \\
\hline IV & $\begin{array}{l}\text { - Significant crushing of concrete } \\
\text { leading to exposure of reinforcing } \\
\text { bars } \\
\text { - Cracks wider than } 2.0 \mathrm{~mm}\end{array}$ \\
\hline $\mathrm{V}$ & $\begin{array}{l}\text { - } \text { Buckling of rebars } \\
\text { - Damage in concrete core } \\
\text { - Column deformation } \\
\text { - Side-sway }\end{array}$ \\
\hline
\end{tabular}

Based on the classification given in Table 5 and the observed damages of the tested structure, damage assessment of the tested structure was conducted. Since the damage is more severe at higher drift ratio, damage class of the tested structure was classified at different drift ratios. Table 6 presents the damage classes of the tested structure at different drift ratios. The tested specimen exhibited the maximum damage class IV at $4.85 \%$ drift ratio.

Table 6. Damage Classes of the Tested Structure at Different Drift Ratios

\begin{tabular}{llllllllllll}
$\begin{array}{l}\text { Drift Ratio } \\
\text { (\%) }\end{array}$ & 0.10 & 0.35 & 0.60 & 0.85 & 1.10 & 1.35 & 1.85 & 2.35 & 2.85 & 3.85 & 4.85 \\
\hline $\begin{array}{l}\text { No. of } \\
\text { Cracks }\end{array}$ & 0 & 1 & 4 & 12 & 17 & 24 & 43 & 48 & 55 & 64 & 69 \\
$\begin{array}{l}\text { Maximum } \\
\begin{array}{l}\text { Crack } \\
\text { Width (mm) }\end{array}\end{array}$ & - & $<0.2$ & $<0.2$ & $<0.2$ & $<0.2$ & 0.2 & 0.8 & 1.2 & 2 & 5 & 6 \\
$\begin{array}{l}\text { Damage } \\
\text { Class }\end{array}$ & - & I & I & I & I & II & II & III & III & IV & IV \\
\hline
\end{tabular}

\section{Conclusions}

In this paper, potential of precast wide $\mathrm{U}$ beam-column system is investigated to mitigate the structural failure from seismic hazard. A half scale specimen of post tensioned precast wide $\mathrm{U}$ beam-column interior joint was tested under displacement controlled lateral cyclic loading. The test results show that the tested specimen exhibited a strong column - weak beam behavior, which is desirable for seismic design of structures. The tested structure did 
not collapse till $4.85 \%$ drift ratio. However, it is noted that the tested structure showed abrupt strength degradation (load drops by $28 \%$ of the peak load). In addition, the tested system exhibits limited ductility with the ductility factors of 2.42 and 2.25 in positive and negative loading cycles, respectively.

Drift capacity obtained from the experiment was used to carry out a displacementbased assessment. The assessment of seismic performance of the tested structure indicates that the drift capacity of the tested system fulfils the demand of all zones with firm soil except the vicinity of Kanchanaburi province. However, the drift capacity of the system based on intermediate and soft soil conditions is insufficient in several locations in Thailand.

Therefore, some future improvements in structural detailing of the system are required to prevent the observed abrupt strength degradation, limited ductility and insufficient drift capacity in order to make the system suitable for all the seismic zones and soil sites in Thailand.

\section{Acknowledgments}

The authors would like to acknowledge Ritta Co., Ltd, Thailand for specimen preparation. This study is financially supported by the Center of Excellence in Material Science, Construction and Maintenance Technology Project, Thammasat University and the Chair Professor Grant (P-19-52302), The National Science and Technology Development Agency (NSTDA), Thailand. In addition, SIIT graduate students, Mr. Hakas Prayuda, Mr. Satish Paudel and Mr. Suphawit Untimanon are acknowledged for assistance in the laboratory.

\section{Glossary of Symbols}

$\begin{array}{ll}\Delta_{\mathrm{f}} & \text { Displacement capacity at effective height (meter) } \\ \Delta_{\mathrm{TC}} & \text { Maximum elastic response displacement (meter) } \\ \Delta_{\mathrm{u}} & \text { Ultimate displacement (millimeter) } \\ \Delta_{\mathrm{y}} & \text { Yield displacement (millimeter) } \\ \mathrm{F}_{\theta} & \text { Factor for higher modes and stiffness variation in different stories } \\ \mathrm{H}_{\mathrm{e}} & \text { Effective height of the building (meter) } \\ \mathrm{H}_{\mathrm{n}} & \text { Height of the building (meter) } \\ \mathrm{M}_{\mathrm{w}} & \text { Moment magnitude of earthquake } \\ \mathrm{PGA} & \left.\text { Peak ground acceleration (m/ } / \mathrm{s}^{2}\right) \\ \mathrm{T}_{\mathrm{c}} & \text { Corner period of the displacement spectra (second) } \\ \mathrm{T}_{\mathrm{f}} & \text { Fundamental period of building (second) } \\ \theta_{\max } & \text { Drift capacity } \\ \mu & \text { Ductility factor }\end{array}$

\section{References}

[1] I. Towhata, Geotechnical Earthquake Engineering, Springer, Berlin, Germany, 2008.

[2] K.M. Onuoha, "Earthquake hazard prevention and mitigation in the West African sub region," In Natural and Man-made Hazards, M.I. El-Sabh, and T.S. Murty, eds: Springer, D. Reidel Publishing Company, Dordrecht, Holland, pp. 787-799, 1988.

[3] I.H. Kim, and J.K. Kim, "Seismic design strategies and details appropriate to moderate seismicity regions," Paper presented at $13^{\text {th }}$ World Conference on Earthquake Engineering, Vancouver, Canada, 2008. 
[4] T. Ornthammarath, P. Warnitchai, K. Worakanchana, S. Zaman, R. Sigbjörnsson, and C.G. Lai, "Probabilistic seismic hazard assessment for Thailand," Bulletin of Earthquake Engineering, Vol. 9, No. 2, pp. 367-394, 2011. doi: 10.1007/s10518-0109197-3

[5] P. Lukkunaprasit, A. Ruangrassamee, T. Boonyatee, C. Chintanapakdee, K. Jankaew, N. Thanasisathit, and T. Chandrangsu, "Performance of structures in the Mw 6.1 Mae Lao earthquake in Thailand on May 5, 2014 and implications for future construction," Journal of Earthquake Engineering, Vol. 20, No. 2, pp. 219-242, 2017. doi: 10.1080/13632469.2015.1051636

[6] Department of Public Works and Town \& Country Planning, Internal Report of the Coordination Center of the Building Damage Assessment Team for the Chiang Rai Earthquake Incidents, Bangkok, Thailand, 2014 (in Thai).

[7] R.P. Bohara, G. Tanapornraweekit, and S. Tangtermsirikul, "Seismic behavior of posttensioned precast wide U beam-column interior joint: A finite element study," Asian Journal of Civil Engineering, Vol. 20, No.4, pp. 603-617, 2019. doi: 10.1007/s42107019-00129-x

[8] R.P. Bohara, G. Tanapornraweekit, and S. Tangtermsirikul, "Behavior of posttensioned precast wide U beam-column exterior connection under lateral cyclic load," Paper presented at $7^{\text {th }}$ Asia Conference on Earthquake Engineering, Bangkok, Thailand, 2018.

[9] Comité Euro-international du Béton, RC Frames under Earthquake Loading: State of the Art Report, Thomas Telford, London, United Kingdom,1996.

[10] J.O. Jirsa, ed., Design of Beam-column Joints for Seismic Resistance, American Concrete Institute, Detroit, Michigan, United States, 1991.

[11] M.J. Priestley, "Displacement-based seismic assessment of existing reinforced concrete buildings," Bulletin of the New Zealand National Society for Earthquake Engineering, Vol. 29, No. 4, pp. 256-272, 1996. doi: 10.5459/bnzsee.29.4.256-272

[12] H.M. Goldsworthy, and K. Abdouka, "Displacement-based assessment of non-ductile exterior wide band beam-column connections," Journal of Earthquake Engineering, Vol. 16, No. 1, pp. 61-82, 2012. doi: 10.1080/13632469.2011.597488

[13] Japanese Society of Civil Engineering (JSCE), "Standard Specification for Concrete Structures, ” Tokyo, Japan, 2007.

[14] Standards New Zealand, Structural Design Actions, Part 5: Earthquake Actions (NZS 1170.5), Wellington, New Zealand, 2004.

[15] P. Warnitchai, and A. Lisantono, "Probabilistic seismic risk mapping for Thailand," Paper presented at $11^{\text {th }}$ world conference on earthquake engineering, pp. 23-28, Acapulco, Mexico, 1996.

[16] S. Pailoplee, and P. Charusiri, "Seismic hazards in Thailand: A compilation and updated probabilistic analysis," Earth, Planets and Space, Vol. 68, No. 1, 2016. doi: 10.1186/s40623-016-0465-6

[17] The Japan Building Disaster Prevention Association, Guideline for Post-earthquake Damage Evaluation and Rehabilitation, Tokyo, Japan, 2001 (in Japanese)..

[18] Y. Nakano, M. Maeda, H. Kuramoto, and M. Murakami, "Guideline for postearthquake damage evaluation and rehabilitation of RC buildings in Japan," Paper presented at 13th World Conference on Earthquake Engineering, Vancouver, British Columbia, Canada. 